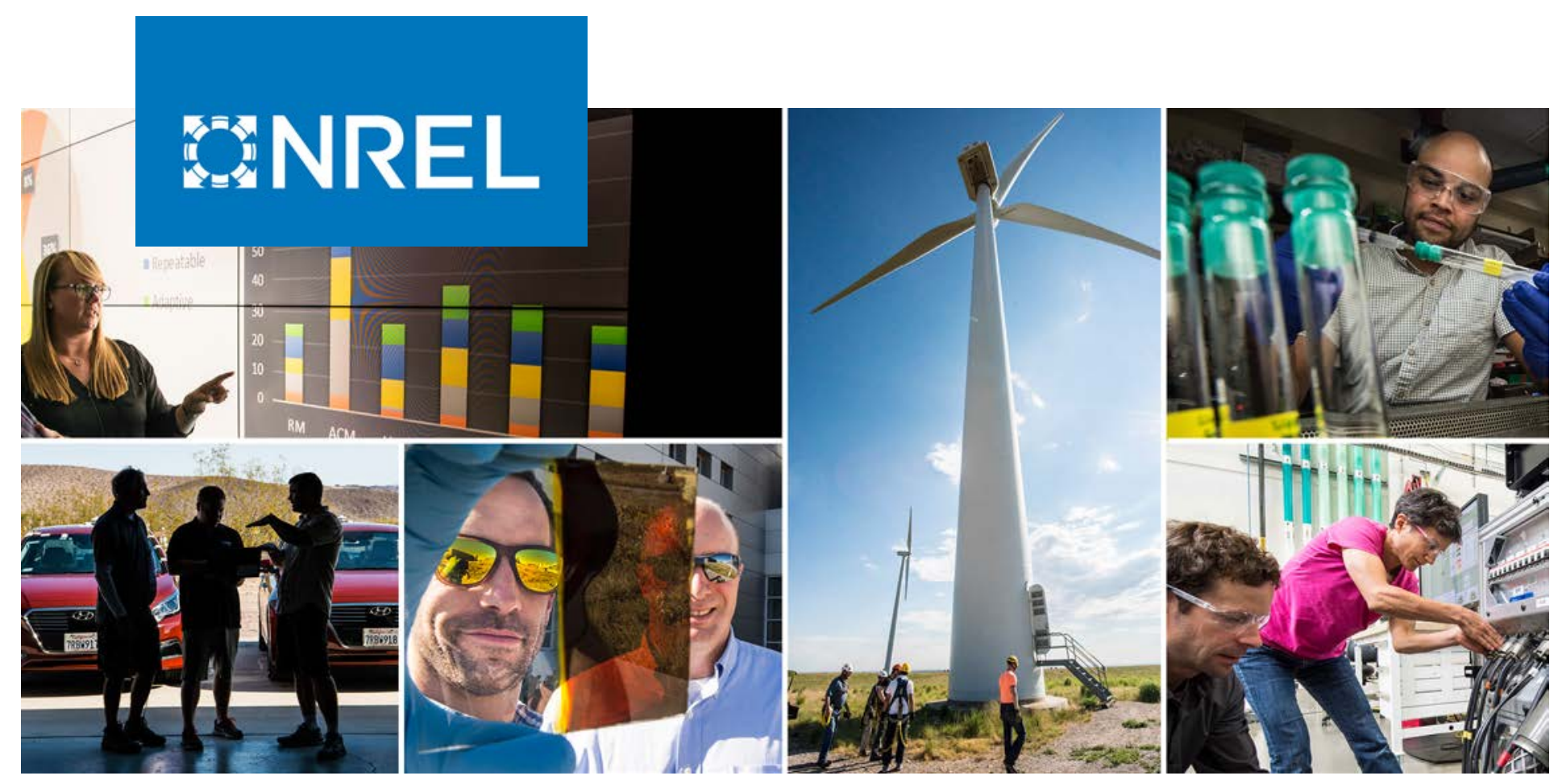

\title{
Modelling the Value of Networked, Small-Hydro Generators for Storage and Dispatch Capability on the Grid
}

\section{Cooperative Research and Development Final Report}

CRADA Number: CRD-17-692

NREL Technical Contact: Greg Stark

NREL is a national laboratory of the U.S. Department of Energy Office of Energy Efficiency \& Renewable Energy

Operated by the Alliance for Sustainable Energy, LLC

This report is available at no cost from the National Renewable Energy Laboratory (NREL) at www.nrel.gov/publications.
Technical Report

NREL/TP-5000-75681

December 2019 


\section{ENREL}

\section{Modelling the Value of Networked, Small-Hydro Generators for Storage and Dispatch Capability on the Grid}

\section{Cooperative Research and Development Final Report}

\section{CRADA Number: CRD-17-692}

NREL Technical Contact: Greg Stark

\section{Suggested Citation}

Stark, Greg. 2019. Modelling the Value of Networked, Small-Hydro Generators for Storage and Dispatch Capability on the Grid: Cooperative Research and Development Final Report, CRADA Number CRD-17-692. Golden, CO: National Renewable Energy Laboratory. NREL/TP-5000-75681. https://www.nrel.gov/docs/fy20osti/75681.pdf.

NREL is a national laboratory of the U.S. Department of Energy Office of Energy Efficiency \& Renewable Energy Operated by the Alliance for Sustainable Energy, LLC

This report is available at no cost from the National Renewable Energy Laboratory (NREL) at www.nrel.gov/publications.

Contract No. DE-AC36-08G028308
Technical Report NREL/TP-5000-75681

December 2019

National Renewable Energy Laboratory 15013 Denver West Parkway Golden, CO 80401 303-275-3000 • www.nrel.gov 


\section{NOTICE}

This work was authored by the National Renewable Energy Laboratory, operated by Alliance for Sustainable Energy, LLC, for the U.S. Department of Energy (DOE) under Contract No. DE-AC36-08GO28308. Funding provided by U.S. Department of Energy Office of Energy Efficiency and Renewable Energy Water Energy Technologies Office. The views expressed herein do not necessarily represent the views of the DOE or the U.S. Government.

This work was prepared as an account of work sponsored by an agency of the United States Government. Neither the United States Government nor any agency thereof, nor any of their employees, nor any of their contractors, subcontractors or their employees, makes any warranty, express or implied, or assumes any legal liability or responsibility for the accuracy, completeness, or any third party's use or the results of such use of any information, apparatus, product, or process disclosed, or represents that its use would not infringe privately owned rights. Reference herein to any specific commercial product, process, or service by trade name, trademark, manufacturer, or otherwise, does not necessarily constitute or imply its endorsement, recommendation, or favoring by the United States Government or any agency thereof or its contractors or subcontractors. The views and opinions of authors expressed herein do not necessarily state or reflect those of the United States Government or any agency thereof, its contractors or subcontractors.

This report is available at no cost from the National Renewable Energy Laboratory (NREL) at www.nrel.gov/publications.

U.S. Department of Energy (DOE) reports produced after 1991 and a growing number of pre-1991 documents are available free via www.OSTI.gov.

Cover Photos by Dennis Schroeder: (clockwise, left to right) NREL 51934, NREL 45897, NREL 42160, NREL 45891, NREL 48097, NREL 46526.

NREL prints on paper that contains recycled content. 


\section{Cooperative Research and Development Final Report}

\section{Report Date: 8/14/19}

In accordance with requirements set forth in the terms of the CRADA agreement, this document is the final CRADA report, including a list of subject inventions, to be forwarded to the DOE Office of Science and Technical Information as part of the commitment to the public to demonstrate results of federally funded research.

Parties to the Agreement: Natel Energy, Inc.

CRADA number: CRD-17-692

CRADA Title: Modelling the Value of Networked, Small-Hydro Generators for Storage and Dispatch Capability on the Grid

Joint Work Statement Funding Table showing DOE commitment:

\begin{tabular}{|l|lc|}
\hline \multicolumn{1}{|c|}{ Estimated Costs } & \multicolumn{1}{|c|}{$\begin{array}{c}\text { NREL Shared Resources } \\
\text { a/k/a Government In-Kind }\end{array}$} \\
\hline Year 1 & $\$$ & $145,000.00$ \\
\hline TOTALS & $\$$ & $145,000.00$ \\
\hline
\end{tabular}

\section{Abstract of CRADA Work:}

Natel Energy, Inc. (Natel), Alameda, California, has developed a new type of fish-friendly, lowhead hydropower turbine, the hydroEngine ${ }^{\circledR}$, that is designed to provide reliable, dispatchable power and ancillary services at significantly reduced civil works costs. For the U.S. Department of Energy's (DOE) Small Business Voucher for Hydropower, Third Round, Natel and NREL will model and evaluate the potential value streams of a portfolio of networked small hydropower generators. The project is designed to advance the understanding of the value of small hydro generation to the grid of the future. It will help support dialog with potential customers and stakeholders regarding the value of the Natel's technologies and inform future R\&D efforts in this area.

\section{Summary of Research Results:}

The U.S. Department of Energy's Small Business Voucher (SBV) program provides American small businesses access to DOE's national laboratories, helping them tap resources to overcome critical technology challenges for advanced energy products. Through this program, Natel utilized NREL's grid analysis capabilities to better understand the potential grid value of a cascading network of Natel's hydroEngine ${ }^{\circledR}$ turbines during dry, typical, and wet operating years. This project used operational optimization to quantifying net revenue and the ability of the system to meet grid needs for varying hydrologic conditions. NREL also assessed operations under multiple operating cost scenarios, storage volumes, market types, and plant locations. 
Both Task 1.0 and Task 2.0 listed below from the original JWS are addressed and detailed in the Summery of NREL's FY20 Work for Natel Energy PowerPoint slide presentation, which served as the final report for DOE SBV and is included within this report below as "Supplemental Documentation A."

Task 1.0: Preliminary Portfolio Model: Identify hydroEngine operational attributes, develop foundational scenarios, and evaluate results of the model runs

1. Build the hydroEngine portfolio model (implement the hydroEngine parameters into a production cost model and verify proper operation)

2. Set up and simulate three scenarios to determine the expected value of the hydroEngine to example systems (e.g., 33\% RPS with conventional flexibility, 50\% RPS with conventional flexibility, and 50\% RPS with enhanced flexibility)

3. Provide a brief, PowerPoint-based report that summarizes the initial results

\section{Task 2.0 Expanded Portfolio Model Including Additional Storage Capability/Operational Flexibility}

Task 2 was rescoped to more appropriately modify the software due to modeling inconsistencies that the vendor was not able to solve in moving to the new platform. We learned that the array of small generators had the ability to deliver energy without negatively impacting stream flow.

The Task 2.0 activities and deliverables will be dependent on the Task 1.0 findings. Activities could include but are not limited to: (This list of task options which could be included were not intended to all be selected for further research. Subtasks not selected are identified in the listing, and selected subtasks are addressed and detailed in the supplemental documentation linked and included in this report below.)

- Exploring the scenario space further with sensitivities on operating practices, grid operating practices (such as regional coordination), gas prices, etc.

- Creating models of various distributed hydropower dispatch capacity (e.g., $500 \mathrm{MW}$ ) and determining the operational value of these portfolios under different scenarios/sensitivities.

- Items that may be explored include:

- The value of a distributed hydro portfolio with integrated storage in CAISO, the EIM, or markets in the Eastern U.S.

- The value of physically hybridizing with various battery configurations (various operational capability and technology may be explored)

- A sensitivity analysis regarding the level of penetration of distributed hydropower networks in certain markets (e.g. $500 \mathrm{MW}, 2 \mathrm{GW}, 5 \mathrm{GW}$ ) (This subtask option was not selected to be pursued.)

- A sensitivity analysis regarding the level of solar penetration in the selected market(s) (This subtask option was not selected to be pursued.)

- A sensitivity analysis regarding Energy Value at various Times of Delivery (e.g., changing hydro dispatch from mid-day to late afternoon/evening) 
- A sensitivity analysis regarding the operational parameters of the Natel turbines (e.g., ability to provide ancillary services, etc.) to determine which parameters are most important for development.

The following publications serve as supplemental information to further detail the work done in Task 2.0:

1. Public journal article Net revenue and downstream flow impact trade-offs for a network of small-scale hydropower facilities in California (https://iopscience.iop.org/article/10.1088/2515-7620/aafd62)

2. Examining the Net Revenue and Downstream Flow Impact Trade-Offs for a Network of Cascading, Small-Scale Hydropower Facilities, an 8-page HydroVision Conference paper which will shortly be published to the OSTI site (included below in this report as "Supplemental Documentation B").

3. As mentioned above, both Task 1.0 and Task 2.0 listed below from the original JWS are addressed and detailed in the Summery of NREL's FY20 Work for Natel Energy PowerPoint slide presentation, which served as the final report for DOE SBV and is included within this report below as "Supplemental Documentation A."

\section{Subject Inventions Listing:}

None

ROI \#:

None

Responsible Technical Contact at Alliance/NREL:

Greg Stark | Greg.Stark@nrel.gov

Name and Email Address of POC at Company:

Abe Schneider | abe@,natelenergy.com

\section{DOE Program Office:}

Small Business Voucher (SBV) Program, Office of Energy Efficiency and Renewable Energy (EERE), Water Technologies Office 


\section{Supplemental Documentation A}

\section{ONREL}

Summary of NREL's FY2018

Work for Natel Energy

Michael Craig and Greg Stark

September 30, 2018

\section{Outline}

- Background on small hydropower and Natel Energy (Natel)

- Analyses originally scoped in contract

- Methods and model development

- Results of analyses

- Conclusion

- Potential extensions 


\section{Background on small hydropower}

- Definitions of small hydropower vary, but generally include units of 1-10 MW in capacity

- Total installed capacity of small hydropower in the United States: $6 \mathrm{GW}$

- Significant additional capacity for deployment exists in the United States and worldwide

- Small hydropower development can occur at existing or new dams, and can be built as run-of-river or with reservoirs

- Development of small hydropower could offer an environmentally friendly, or even beneficial, generation source

Natel developed a new micro hydropower turbine that it aims to deploy in California

- Natel Energy:

- employs approximately 40 people in Oakland, CA

- asked us to investigate deployment of 36 turbines in sequence along a river in Northeastern California

- Natel's hydroEnergy turbine:

- uses a Linear Pelton designed to operate at high flows (8-10 $\mathrm{m}^{3} / \mathrm{s}$ ) and low heads (7-19 $\mathrm{m}$ )

- couples with small reservoirs

- offers power capacities that range from 0.5-1 $\mathrm{MW}$

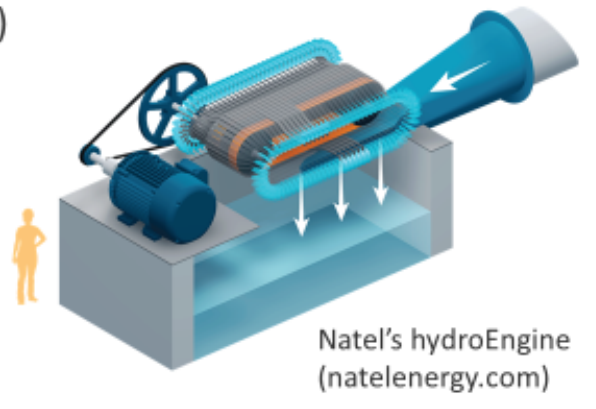




\section{Analyses included in contract}

- The original Natel CRADA included two tasks:

- Task 1.0: Preliminary Portfolio Model-Identify hydroEngine operational attributes, develop foundational scenarios, and evaluate results of the initial model runs

- Construct an operational model of Natel's turbines

- Run model to quantify expected value of Natel's turbines in 3 example systems with varying renewable penetrations

- Status: completed (two IID models, one Yuba River model)

- Task 2.0: Expanded Portfolio Model, Including Additional Storage Capability/Operational Flexibility

- Conduct sensitivities, e.g., on operating practices, reservoir sizes, hybrid reservoir/battery storage, etc.

- Status: rescoped to address modeling infeasibilities; completed revised scope via a price-taker approach

\section{Methods overview}

- To complete Task 1.0, we needed to construct models capable of capturing the details of, and interdependencies between, operations of cascading and parallel facilities

- We investigated modeling options for quantifying outcomes:

1. Production cost modeling (Imperial Irrigation District, IID)

- 1a: embed facilities into a small production cost model, then optimize operations over the small test system

- $1 \mathrm{~b}$ : scale the facilities in the production cost model so that the model better matched Imperial Irrigation District's operations, then optimize operations with rest of system

2. Price-taker modeling (Yuba River)

- assume the Natel facilities are price takers (i.e., their operations do not affect prices), then optimize operations given an exogenous price time series 


\section{Imperial Irrigation District Test System}

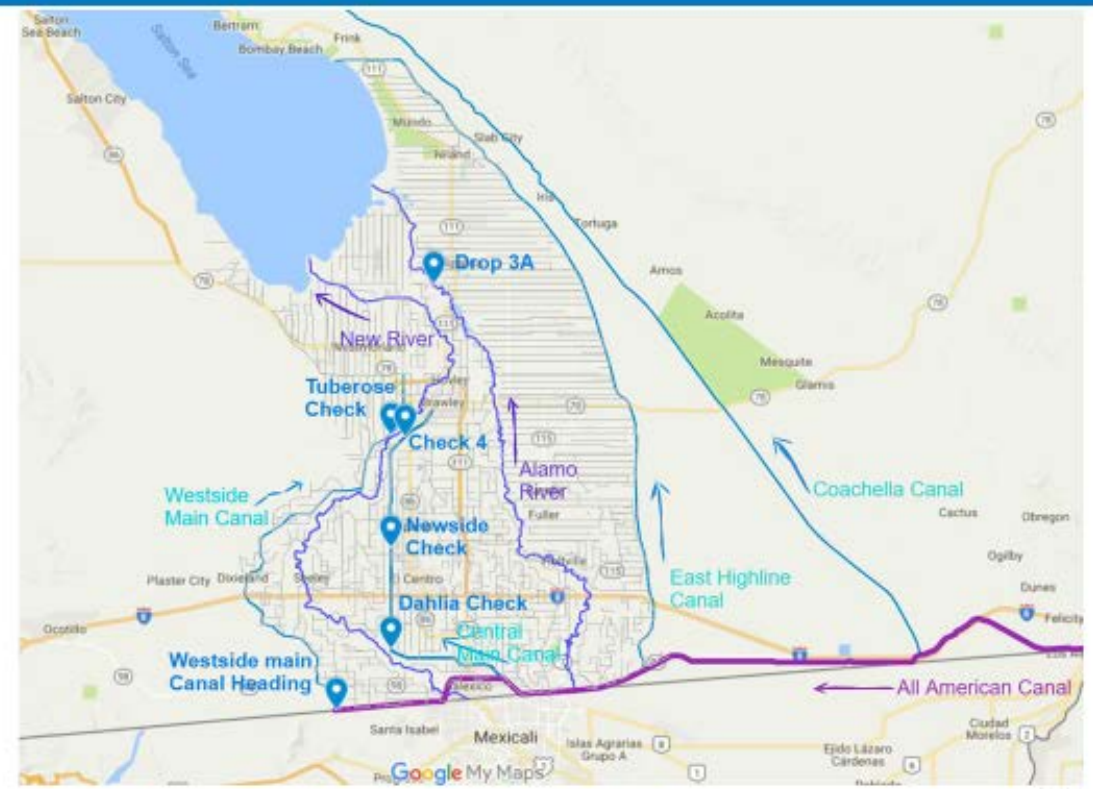

NREL $\mid 7$

\section{Yuba River Test System}

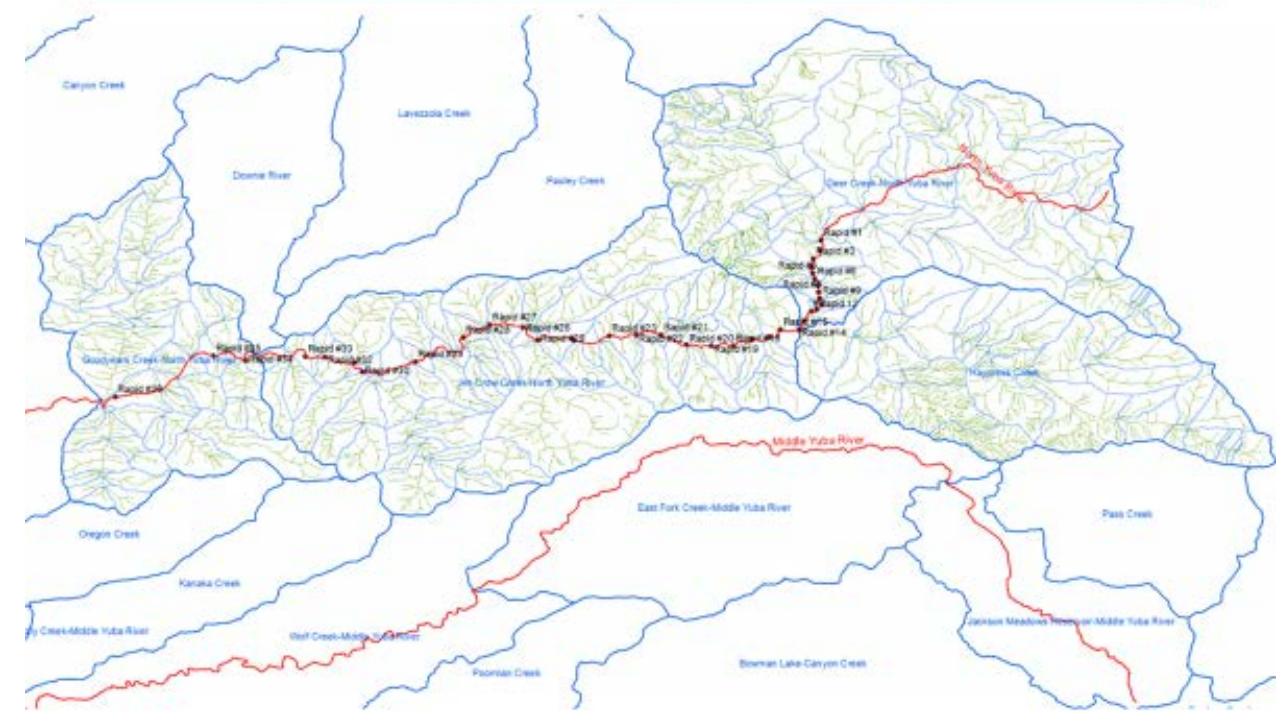




\section{Production cost methods findings}

- To prototype the production cost modeling methodologies, we built two models, both based on a 5-bus grid test system:

- Option 1a: embed Natel facilities into a limited, primarily cascading production cost model, then optimize operations with the balance of the system

- Option 1b: expand the system so that it represented IID's generation mix, hydroEngine generation efficiencies as a function of storage depth, and real-time load

- Early in our generation efficiency study work, we identified infeasibilities that we were unable to resolve even after working with the software vendor, Energy Exemplar; these modeling challenges limited our ability to move forward

- Consequently, we moved to the price-taker (net-revenue maximization) model for the remainder of the project

\section{Price-taker methods overview}

- Use of the price-taker model allowed increased control over system representation, and we were better able to capture details of, and interdependencies between, operations of the 36 facilities (e.g., we could investigate effects of changing storage depth on generation)

- Each generating station varied from 0.5 to $1 \mathrm{MW}$ in capacity and had between 1 and 45 minutes of full-capacity energy storage

- Given that the peak load in California is approximately $1,000 x$ the capacity of the Natel generation array, we felt confident that the price-taker assumptions were valid

- By choosing the price-taker approach, we were able to investigate more sensitivities, e.g., generator efficiency as a function of reservoir depth, storage volume contributions (e.g., does increasing reservoir size or adding batteries improve a unit's profitability), etc.

- The remainder of this report is based on results from our price-taker modeling work 


\section{Natel's priorities and turbines' characteristics drove the design of our model to estimate revenues}

\begin{tabular}{|c|c|}
\hline $\begin{array}{l}\text { Motivating Technology Characteristic or } \\
\text { Desired Feature }\end{array}$ & Model Design Implication \\
\hline $\begin{array}{l}\text { Combined capacity of Natel's turbines are } \\
\text { small relative to total system capacity }\end{array}$ & $\begin{array}{c}\text { Model maximizes net revenues of turbines } \\
\text { assuming they are price takers }\end{array}$ \\
\hline $\begin{array}{l}\text { Natel cares about profitability and } \\
\text { environmental impacts }\end{array}$ & $\begin{array}{l}\text { Model constrains operations to minimize } \\
\text { streamflow impacts }\end{array}$ \\
\hline $\begin{array}{l}\text { Natel plans initial deployment in California } \\
\text { ISO }\end{array}$ & $\begin{array}{l}\text { Model optimizes operations across energy } \\
\text { and multiple ancillary service markets }\end{array}$ \\
\hline $\begin{array}{l}\text { Natel plans to deploy } 36 \text { turbines in } \\
\text { sequence along } 1 \text { river }\end{array}$ & $\begin{array}{l}\text { Model captures impacts of upstream turbines } \\
\text { on downstream turbines }\end{array}$ \\
\hline $\begin{array}{l}\text { Low-head turbines have non-linear stored } \\
\text { water volume and generation functions }\end{array}$ & $\begin{array}{l}\text { Model uses piecewise linear approximations } \\
\text { for stored volume and generation }\end{array}$ \\
\hline $\begin{array}{c}\text { Natel may deploy technology in other } \\
\text { regions }\end{array}$ & $\begin{array}{l}\text { Model's flexibility permits its application to } \\
\text { estimate revenues in other systems }\end{array}$ \\
\hline
\end{tabular}

\section{Given these model design requirements, we developed a profit-maximization model}

\section{Key Inputs}

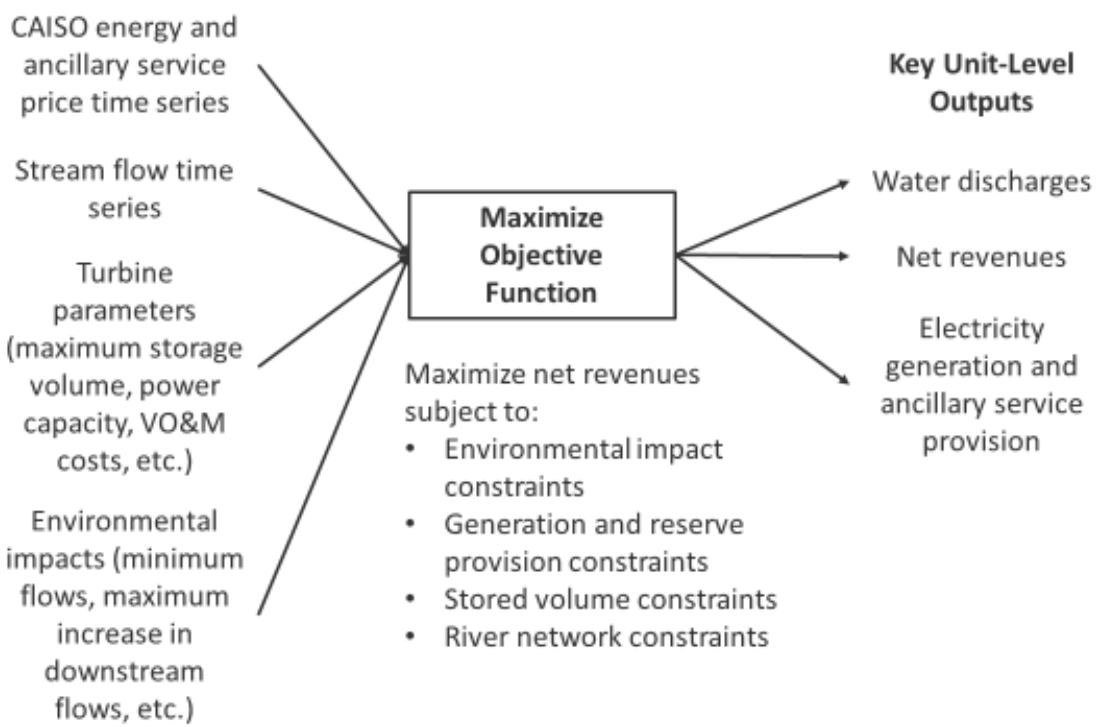




\section{Results}

- We conducted multiple analyses for Natel under each Task

- Task 1.0: Preliminary Portfolio Model-Identify hydroEngine operational attributes, develop foundational scenarios, and evaluate results of the model runs

- Analyses: developed detailed operational model, then quantified net revenues across years, markets, and services; quantified total storage potential of facilities

- Task 2.0: Expanded Portfolio Model Including Additional Storage Capability/Operational Flexibility

- Analyses: tested net revenue sensitivity to variable O\&M costs, limits on downstream flow impacts, reservoir storage capacities, etc.

\section{We estimated Natel's net revenues in three years that} represented diverse hydrological conditions and the associated electricity and ancillary service prices

- We conducted our analysis for three years of data that capture dry (2015), typical (2016), and wet (2017) flow years

- Optimized generation array mostly provides electricity rather than ancillary services

- Annual net revenues vary from $\$ 0.5$ to $\$ 2.2$ million

\begin{tabular}{|c|c|c|c|}
\hline & $\begin{array}{c}\text { Annual Net } \\
\text { Revenue } \\
\text { (million \$) }\end{array}$ & $\begin{array}{c}\text { Total Electricity } \\
\text { Generation } \\
\text { (GWh) }\end{array}$ & $\begin{array}{l}\text { Total Regulation } \\
\text { Up Provision } \\
\text { (GWh) }\end{array}$ \\
\hline 2015 (dry) & 0.5 & 55 & 0.1 \\
\hline 2016 (typical) & 0.9 & 93 & 0.1 \\
\hline 2017 (wet) & 2.2 & 142 & 0.1 \\
\hline
\end{tabular}




\section{Net revenues varied across months for a given year, and across years for a given month}
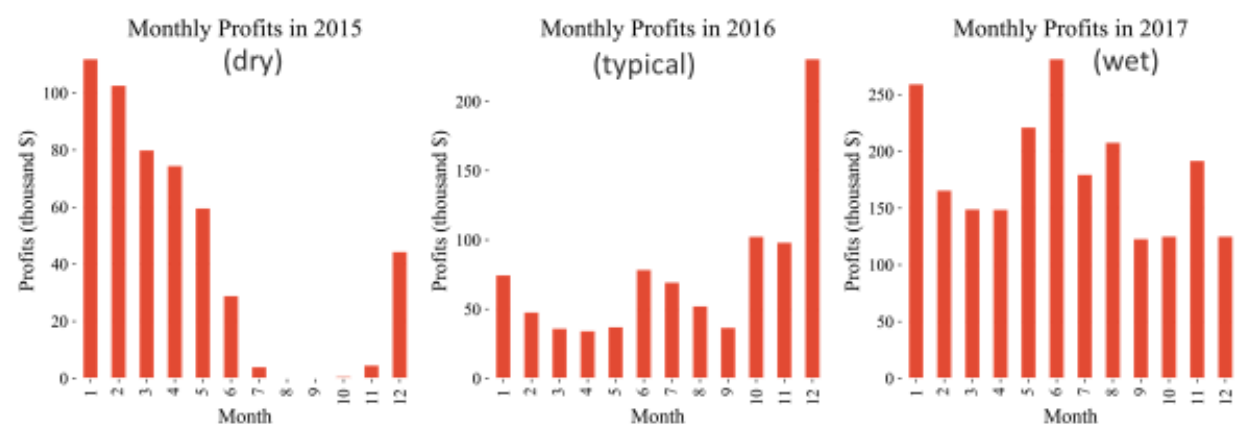

- Monthly net revenues are driven by the interaction of electricity prices and stream flows

- Insufficient stream flows in summer preclude operations despite high electricity prices

- Low prices in spring preclude operations despite high stream flows (prices were less than hydroEngine operating costs)

\section{Facilities' typical daily operations followed pricing}

\section{signals, peaking in late morning and evening}

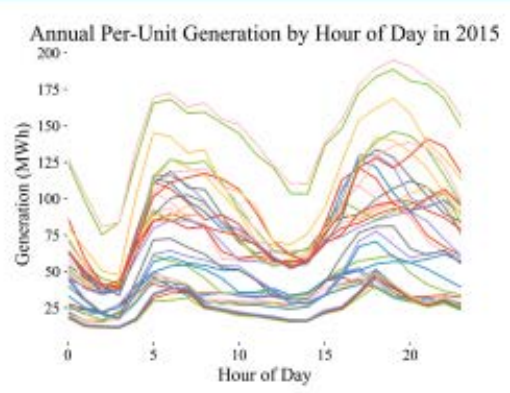

Annual Per-Unit Generation by Hour of Day in 2016

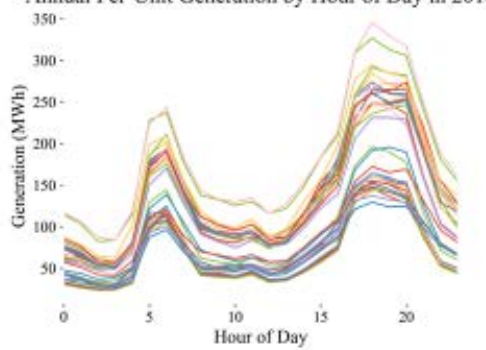

Annual Per-Unit Generation by Hour of Day in 2017

Plots show generation by hour of day summed across the entire year, with each line representing one facility.

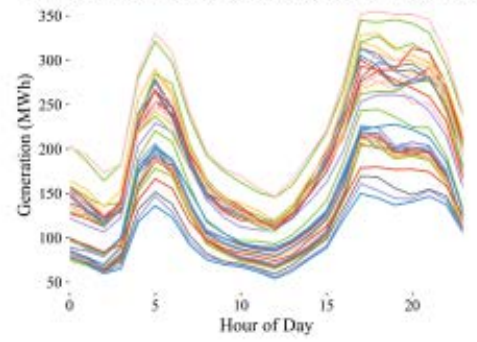




\section{Net revenues were greater in real-time than day- \\ ahead markets, but inter-year variability of net \\ revenues exceeds inter-market variability}

- Optimized Natel operations assuming it operates in the day-ahead OR 15-minute real-time market.

- Average prices are higher in DAM, but peak prices are higher in RTM.

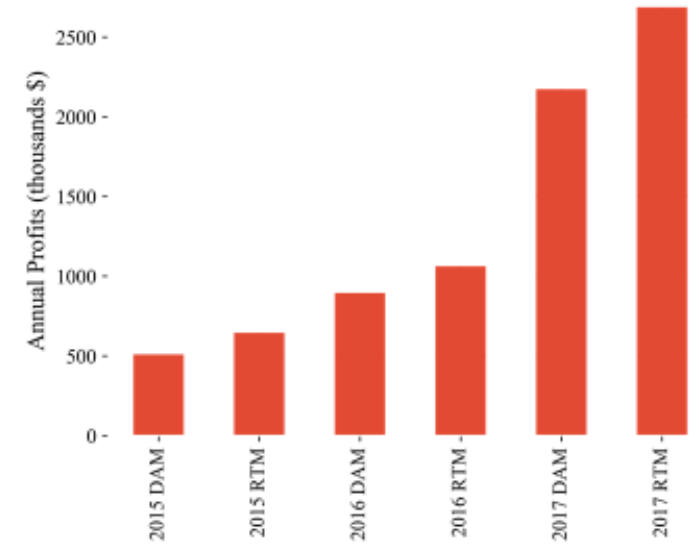

\section{We also quantified the total storage potential of Natel's 36 hydropower facilities}

- Rising penetrations of variable generation (wind and solar) are increasing system needs for flexibility

- CAISO has implemented a flexibility market product

- We quantified two measures of total storage potential:

- 1) Potential generation by each facility using water stored in its reservoir

- Total storage: $8.82 \mathrm{MWh}$

- 2) Potential generation by each facility and all downstream facilities using water stored in its reservoir

- Captures cascading nature of releases from one facility to downstream facilities

- Total storage: $87 \mathrm{MWh}$ 


\section{Related to storage potential, we also quantified the value of stored water in facilities' reservoirs}

- Natel is considering changing reservoir storage volumes (this also captures the effects associated with adding battery storage)

- We quantified the sensitivity of 2016 (typical hydrological year) net revenues to changes in the maximum stored volume in each facility's reservoir

- Doubling reservoir volumes increased net revenues by $6 \%$, while quartering reservoir volumes reduced them by $17 \%$

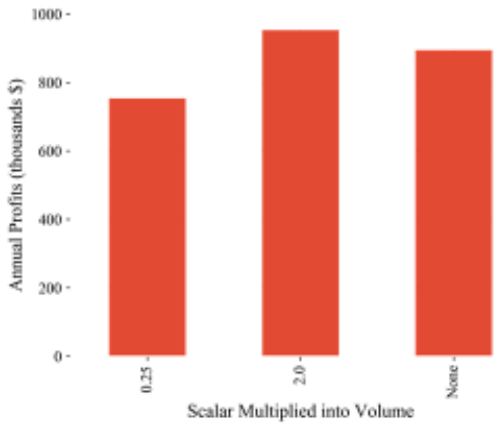

\section{We conducted several sensitivity analyses on our} results, including on variable O\&M costs

- Natel requested this sensitivity for a typical hydrological year to guide their ongoing work to reduce hydroEngine O\&M costs

- We found large, non-linear variations in 2016 net revenues (i.e., typical year net revenues) as VO\&M costs changed (e.g., a $25 \%$ reduction in VO\&M costs, from $\$ 24 / \mathrm{MWh}$ to $\$ 18 / \mathrm{MWh}$, would increase Natel's profits by $82 \%$ for a typical hydrological year)
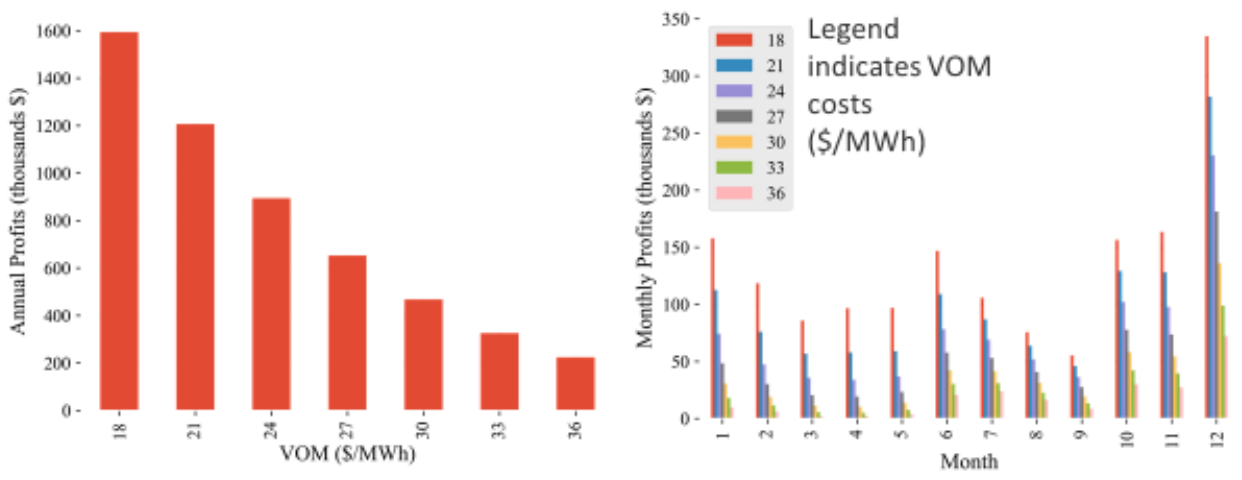

NREL $\mid 20$ 


\section{Given Natel's interest in environmentally friendly}

operations, we also examined the trade-off between net revenues and downstream flow impacts

- Optimizing operations by maximizing net revenues resulted in significant increases (by up to 10 times) in downstream flows.

- We quantified net revenues in 2016 (typical hydrological year) when limiting downstream impacts by limiting each facility's discharges to a percent of "natural" downstream flows (i.e., downstream flows unperturbed by facilities' operations).

- Submitted a paper, Net Revenue and Downstream Flow Impact Trade-offs for a Network of Small-Scale Hydropower Facilities in California, for review to Environmental Research Notes

\section{We found downstream flow impacts could be minimized with minimal impact on net revenues}

- Electricity generation increases under operational constraints due to increased generation by upstream facilities (next slide)

- Difference in net revenues between no operational constraints ("None") and constraining operations to increasing downstream flows by only $5 \%$ (" 0.05 ") is less than $1 \%$ across years.

- Indicate little trade-off between economics and environment for Natel.
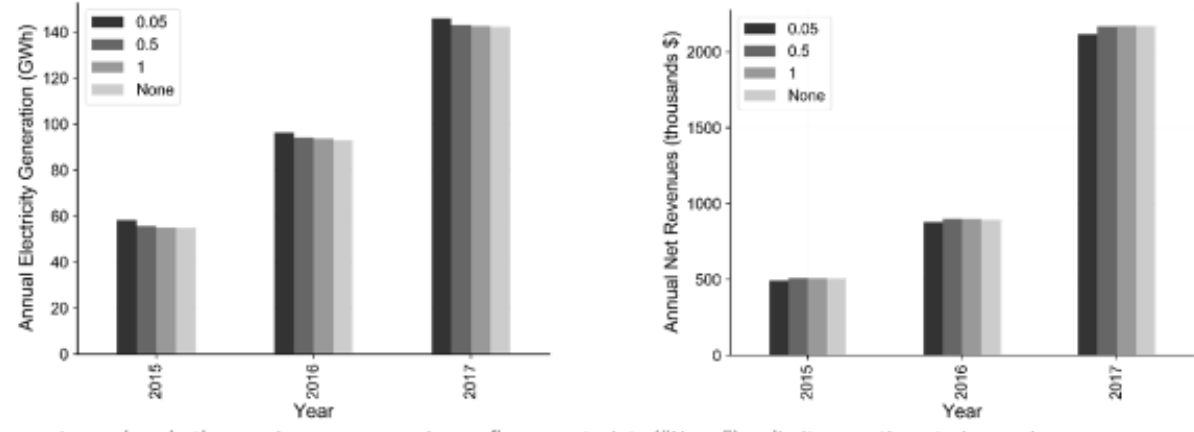

Legends: whether we impose no maximum flow constraints ("None") or limit operations to increasing downstream flows by $5 \%\left(" 0.05^{\prime \prime}\right), 50 \%\left(" 0.5^{\prime \prime}\right)$, or $100 \%(" 1 ")$. 
Downstream flow impact constraints have little impact on total net revenues because net revenues increase at upstream facilities and decrease at downstream facilities

- Without flow constraints, upstream facilities discharge water at sub-optimal periods (with respect to net revenues) so that the water yields generation at downstream facilities at optimal periods.

- Flow constraints limit downstream facilities' operations, so upstream facilities instead discharge water at optimal periods, increasing their net revenues.
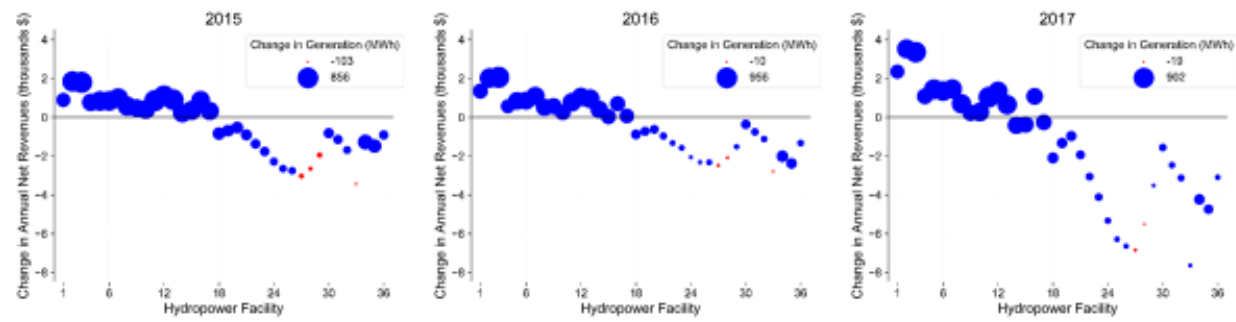

Figures: change in annual net revenues for each hydropower facility in each year from no maximum flow constraints to the 0.05 maximum flow constraint scenario. Points are scaled based on the magnitude of each facility's change in electricity generation and colored based on whether each facility's generation increased (blue)

or decreased (red) between the same two scenarios. Hydropower Facility 1 is the farthest upstream.

\section{Conclusions (1 of 2 )}

- To address Natel's economic and environmental priorities and the unique features of its technology, we developed a net-revenue-maximizing model that captures both economic and environmental considerations

- Using this model, we estimated net revenues in different years and markets; examined economic and environmental trade-offs; quantified total storage potential and the value of stored water; conducted several sensitivity analyses to guide Natel's future efforts; and performed other analyses for Natel

- Significant findings from the Yuba River price-taker model:

- Net revenues were between 16 and $25 \%$ greater in the real-time markets than in the day-ahead markets

- Inter-year (wet vs. typical vs. dry) variability in net revenues exceeds intermarket variability (net revenues for a wet year were $4 x$ those of the dry year)

- Doubling storage volumes increases net revenues by only $6 \%$; quartering storage volumes reduces net revenues by $17 \%$

- Reducing VO\&M costs by $25 \%$ is expected to increase net revenues by over $80 \%$ in a typical year (the system was found to be very sensitive to VO\&M costs)

- Downstream flow impact constraints have little impact on total net revenues (less than $1 \%$ across years) 


\section{Conclusions ( 2 of 2 )}

- Based on our analysis of economic and environmental benefits and trade-offs, we submitted a joint paper (NREL and Natel Energy) for review to Environmental Research Notes

- We also designed the model to facilitate its use in other power systems, with forecasted prices, and with similar technologies (e.g., we've since used the model in both the Ternary and Obermeyer projects).

\section{Potential Extensions}

- Model Natel operations in future systems or market conditions

- Quantify impact of increasing renewable penetrations

- $100 \%$ decarbonization law recently passed in California

- CAISO market reforms ongoing (flexibility products, etc.)

- Modify model to co-optimize net revenues and environmental restoration

- Rather than maximize revenues while limiting impacts, could maximize revenues as well as stream restoration metrics

- Extend model for use in investigating additional to grid effects:

- Impacts on emissions

- Value of flexibility

- Integration of renewable energy

- Further develop the model to make it easier to use and customize, and then release it to industry and/or the public 


\section{GNREL}

Thanks to Natel Energy and the U.S. Department of Energy for making this research possible.

Please send any questions or comments to michael.craig@nrel.gov and greg.stark@nrel.gov.

This work was authored by Alliance for Sustainable Energy, LLC, the Manager and Operator of the National Renewable Energy Laboratory for the U.S. Department of Energy (DOE) under Contract No. DE-AC36-08GO28308. Funding provided by the U.S. Department of Energy Office of Energy Efficiency and Renewable Energy Water Power Technologies Office. The views expressed in the article do not necessarily represent the views of the DOE or the U.S. Government. The U.S. Government retains and the publisher, by accepting the article for publication, acknowledges that the U.S. Government retains a nonexclusive, paid-up, irrevocable, worldwide license to publish or reproduce the published form of this work, or allow others to do so, for U.S. Government purposes. 


\section{Supplemental Documentation B}

\section{Examining the Net Revenue and Downstream Flow Impact Trade-Offs for a Network of Cascading, Small-Scale Hydropower Facilities}

Michael Craig ${ }^{1}$, Jin Zhao ${ }^{2}$, Gia Schneider ${ }^{2}$, Abe Schneider ${ }^{2}$, Sterling Watson ${ }^{2}$, and Greg Stark ${ }^{3,4}$

\section{Abstract}

In this work, we used a price-taker model to investigate the trade-offs between net revenue and downstream flow impacts for a network of small, cascading hydro facilities. The network consisted of 36 facilities, each with a small amount of local storage (between 2 and 45 minutes). Generator sizes ranged between 0.5 and $1 \mathrm{MW}$, nominal, and the total capacity of the network was 33.5 MW. We used a multi-integer linear programing model to maximize the net revenue of the combined network subject to operating and environmental constraints. Net revenue optimizations relied on historic price data, and dry, typical, and wet years were studied to help ensure robustness. Energy and ancillary service sales were included in the net revenue calculations, and both unit commitment and dispatch simulations were performed. We found that limiting the downstream flows to $\pm 50 \%$ of the river's natural flows had a negligible impact on net revenues ( $<1 \%$ reduction), irrespective of hydrologic conditions, and even when downstream flows were limited to $\pm 5 \%$, net revenues were only impacted by $4 \%$. These outcomes are significant because they demonstrate how an array of small-scale hydropower facilities can be operated to have minimal impact on natural stream flows - addressing a critical environmental concern.

\section{Introduction}

One of the challenges associated with conventional, large-scale hydropower (>50 MW) is the local environmental impact on stream flows and water quality, and investigating how smallscale hydropower ( $<10 \mathrm{MW})$ might help mitigate these consequences was the inspiration for the research presented here. We examined how the co-optimization of the operation of a 36- station array of cascading small hydro facilities would perform economically while ensuring minimal impact to river flows. This work was conducted by the National Renewable Energy Laboratory and Natel Energy, as a part the U.S. Department of Energy Office of Energy Efficiency and Renewable Energy's Small Business Voucher program. ${ }^{5}$

\footnotetext{
1 University of Michigan School for Environment and Sustainability, 440 Church Street, Ann Arbor, MI 48109 (Michael performed this research while at the National Renewable Energy Laboratory)

2 Natel Energy, 2401 Monarch Street, Alameda, CA 94501

3National Renewable Energy Laboratory, 15013 Denver West Parkway, Golden, CO 80401

4 Corresponding author: Greg.Stark@nrel.gov

5 EERE's Small Business Vouchers (SBV) program opens the national labs to qualified clean energy small businesses by making the contracting process simple, lab practices transparent, and access to the labs' unique facilities affordable. Most importantly, SBV gives U.S. clean energy small businesses an incredible competitive advantage in the global marketplace and increases national lab awareness of the challenges small businesses face in the energy sector (please see https://www.energy.gov/eere/technology-to-market/small-business-vouchers for more information).
} 


\section{Background}

Concerns about how water impoundment and the large fluctuation in downstream flows affects the quality of river systems has been an ongoing concern for a number of years (Kern et al. 2012, Jager and Bevelhimer 2007). Earlier work examined whether dams could be operated so that they mimicked natural stream flows by changing their operations from load following to run of river. Kern et al. (2012) investigated how varying the operational paradigm for a single, large hydropower plant located in PJM's operational area would affect that facility's net revenues. They found that by switching from a load-following to a run-of-river approach would reduce annual revenues by up to $15 \%$. Similarly, Jager and Bevelhimer (2007) performed a retrospective analysis of hydropower facilities that had changed from peaking to run-of-river operations, and they found that most facilities had reduced generation efficiency; however, they did not quantify how these changes affected revenues. Common to both studies is that plant operations were examined in isolation, that is, separate from other river operations (e.g., cascading plants were not considered).

The current work builds on the previously mentioned efforts and investigates whether a series of cascading, small, low-head hydropower plants can be operated in a manner to minimize the impacts to water quality while not significantly reducing operational revenue (with downstream flows serving as a proxy for water quality).

\section{Test System}

The system under study comprises 36 small-scale hydropower facilities designed by Natel Energy (2018). Each facility used one of two hydroEngine linear Pelton impulse turbines, with the choice being dependent on the head available for the given facility (see Table 1).

Table 1. hydroEngine Types and Capabilities

\begin{tabular}{|c|c|c|}
\hline $\begin{array}{c}\text { hydroEngine } \\
\text { type }\end{array}$ & $\begin{array}{c}\text { Number of } \\
\text { facilities }\end{array}$ & $\begin{array}{c}\text { Average power (min-max) at } \\
\text { maximum head height [MW] }\end{array}$ \\
\hline 1 & 32 & $1.0(0.93-1.06)$ \\
\hline 2 & 4 & $0.5(0.46-0.51)$ \\
\hline
\end{tabular}

The linear Pelton design provides excellent rangeability, and the power output of the units can increase from zero to maximin capacity (and vice versa) within a matter of minutes. Additional information about the hydroEngine turbines can be found at Natel Energy's website (Natel Energy 2018).

Each turbine was coupled to a 2-meter-deep forebay, and the storage volumes of the forebays ranged from 0.02 to $0.77 \mathrm{MWh}$ of stored energy $\left(700-49,000 \mathrm{~m}^{3}\right)$. The units were deployed in a cascading manner, with upstream units feeding the reservoir of units downstream. When summed across all 36 facilities, the stored energy equates to $8.82 \mathrm{MWh}$, with a nameplate capacity of 33.5 MW. Accounting for downstream generation, the stored energy ranges between 0.59 and 5.98 MWh for each station (the amount of storage varies with both reservoir size and a facility's position in the cascade) and $87 \mathrm{MWh}$ across all facilities. 
For purposes of the study, historic flow information from the U.S. Geological Survey's Goodyear Bar gaging station on the Yuba River, located in Sierra County in Northeastern California, was used (U.S. Geological Survey 2018). The 36 generating stations were deployed in a cascading manner and located over a 36-km stretch of the river upstream of Goodyear Bar, with the traversal times between facilities ranging between 0.10 and 1.90 hours, respectively. Fifteen- minute flow data were used, and facility-specific flows (i.e., upstream flows at each generating station) were calculated based on a ratio of each facility's drainage area and the Goodyear Bar drainage area. To ensure robustness in the results, data for dry (2015), typical (2016), and wet (2017) years were used.

Additional information about the test system can be found in Craig et al. (2019).

\section{Analytical Approach}

In order to characterize how constraining downstream flows affects generator revenue, we used a multi-integer linear programming model that optimized the net revenue subject to operating and environmental constraints. These constraints limited downstream flow impacts and represented machine performance characteristics, cascading flows between facilities, minimum flow requirements, and nonlinear power generation and reservoir volume relationships. The nonlinear aspects of the problem were simplified by using piecewise linear approximations (e.g., the head to available power relationship for each facility was modeled as a two-piece linear approximation).

Net revenue consisted of energy and ancillary service revenues, including mileage payments, minus variable operation and maintenance costs (California Independent System Operator [CAISO] 2016). We used a price-taker approach given the test system's small size (33.5 MW) relative to the amount of generation in CAISO's footprint (CAISO has over 50,000 MW of capacity). Net revenue optimizations relied on historic price data from CAISO's northern zone (NP15), and both day-ahead unit commitment and hourly dispatch optimizations were performed for all three study years (CAISO 2017).

To capture the water transversal times (up to 15 hours from the first to last facility), we ran the model with a 15 -hour window plus 2-hour look-ahead period. 
Table 2. Characteristics That Drove Model Design

\begin{tabular}{|l|l|}
\hline \multicolumn{1}{|c|}{$\begin{array}{c}\text { Motivating Technology Characteristic or } \\
\text { Desired Feature }\end{array}$} & \multicolumn{1}{|c|}{ Model Design Implication } \\
\hline $\begin{array}{l}\text { Combined capacity of Natel's turbines are small } \\
\text { relative to total system capacity }\end{array}$ & $\begin{array}{l}\text { Model maximizes net revenues of turbines } \\
\text { assuming they are price takers }\end{array}$ \\
\hline $\begin{array}{l}\text { Natel cares about profitability and } \\
\text { environmental impacts }\end{array}$ & $\begin{array}{l}\text { Model constrains operations to minimize } \\
\text { streamflow impacts }\end{array}$ \\
\hline $\begin{array}{l}\text { Natel plans initial deployment within CAISO's } \\
\text { footprint }\end{array}$ & $\begin{array}{l}\text { Model optimizes operations across energy and } \\
\text { multiple ancillary service markets }\end{array}$ \\
\hline $\begin{array}{l}\text { Natel plans to deploy } 36 \text { turbines in sequence } \\
\text { along one river }\end{array}$ & $\begin{array}{l}\text { Model captures impacts of upstream turbines on } \\
\text { downstream turbines }\end{array}$ \\
\hline $\begin{array}{l}\text { Low-head turbines have nonlinear stored water } \\
\text { volume and generation functions }\end{array}$ & $\begin{array}{l}\text { Model uses piecewise linear approximations for } \\
\text { stored volume and generation }\end{array}$ \\
\hline Natel may deploy technology in other regions & $\begin{array}{l}\text { Model's flexibility permits its application to } \\
\text { estimate revenues in other systems }\end{array}$ \\
\hline
\end{tabular}

The primary factors that drove the model design are summarized in Table 2, and a schematic of the resulting model is shown in Figure 1. Note that the model was constructed so that it would be easy to adapt for other study types (e.g., in related work, we performed studies that examined how variable operation and maintenance, VO\&M, costs impacted net revenues) as well as study areas (the model was designed so that market products are easy to configure, and the market product price streams are read from csv files).

Additional information about the analytical approach and the resulting model can be found in Craig et al. (2019).

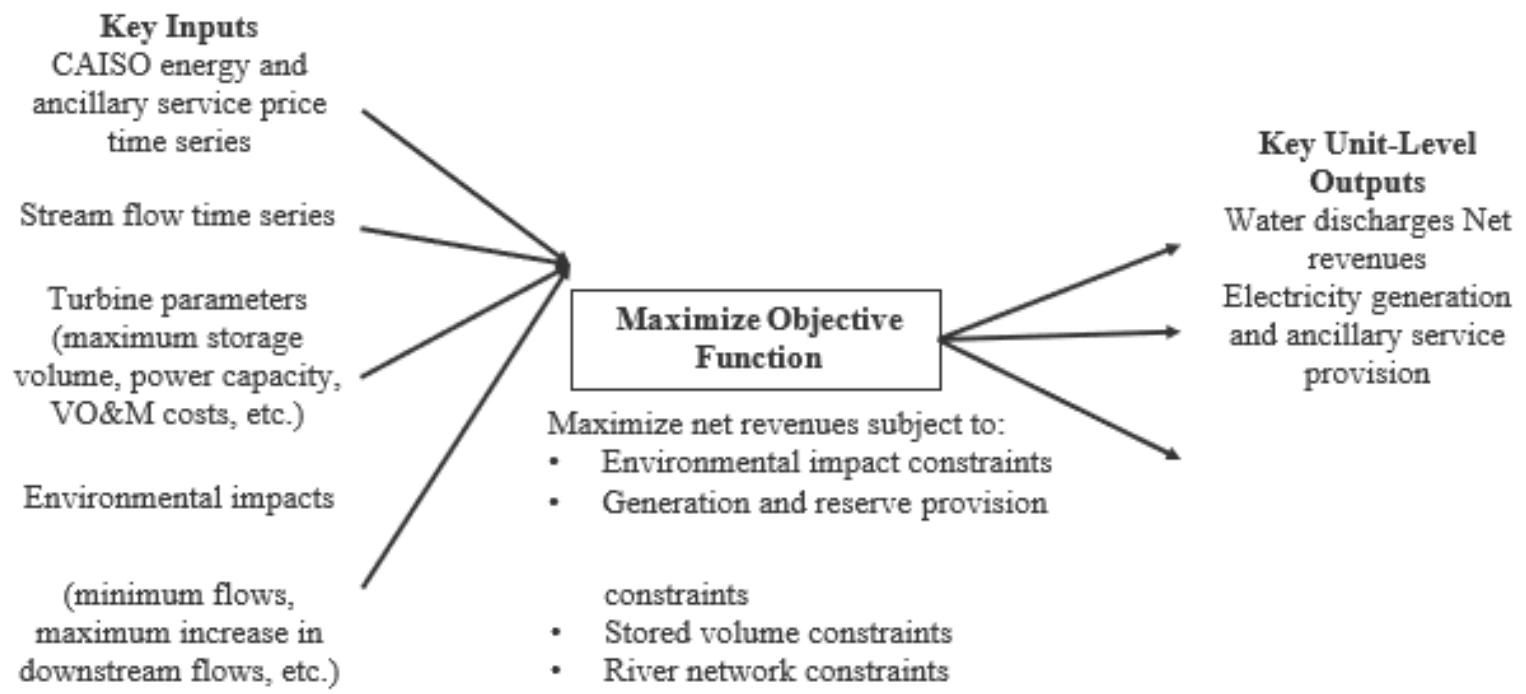

Figure 1. Profit maximization model 


\section{Results}

Two types of scenarios were performed: one that investigated how limiting downstream flows would impact plant revenues, and another that examined role reservoir size on net revenues.

The nominal annual electricity generation and net revenues for the dry, typical, and wet years are shown in Table 3.

Table 3. Annual Generation and Net Revenue for the Combined Facilities

\begin{tabular}{|c|c|c|}
\hline Year (conditions) & Annual Generation (GWh) & Annual Net Revenue (thousands \$) \\
\hline 2015 (dry) & 55 & 500 \\
\hline 2016 (typical) & 93 & 900 \\
\hline 2017 (wet) & 142 & 2,200 \\
\hline
\end{tabular}

These values can be used to provide context for how limiting downstream flows affects annual generation and net revenues.

\section{Downstream Flow vs Revenue}

The primary study goal was to investigate how limiting downstream flows (i.e., adding additional environmental constraints) would impact the net revenues for the 36-station test system given its cascading configuration.

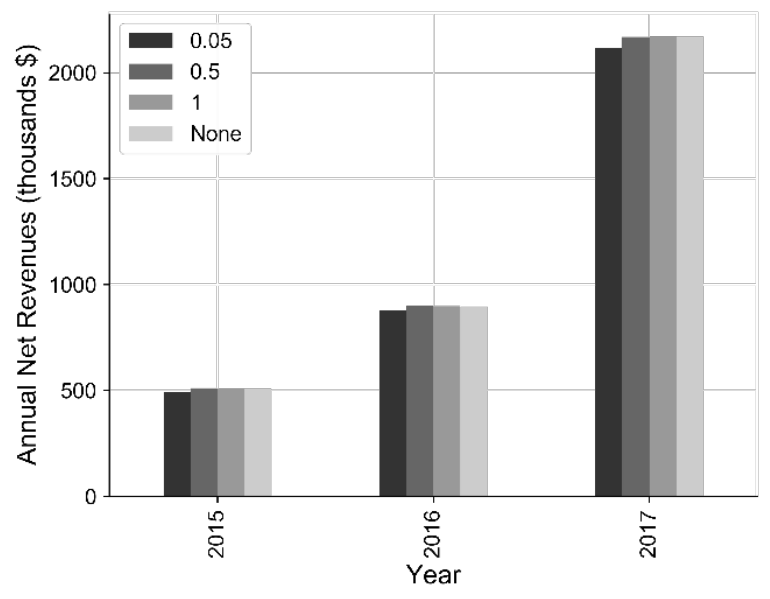

Figure 2. Annual net revenue as a function of flow constraint 


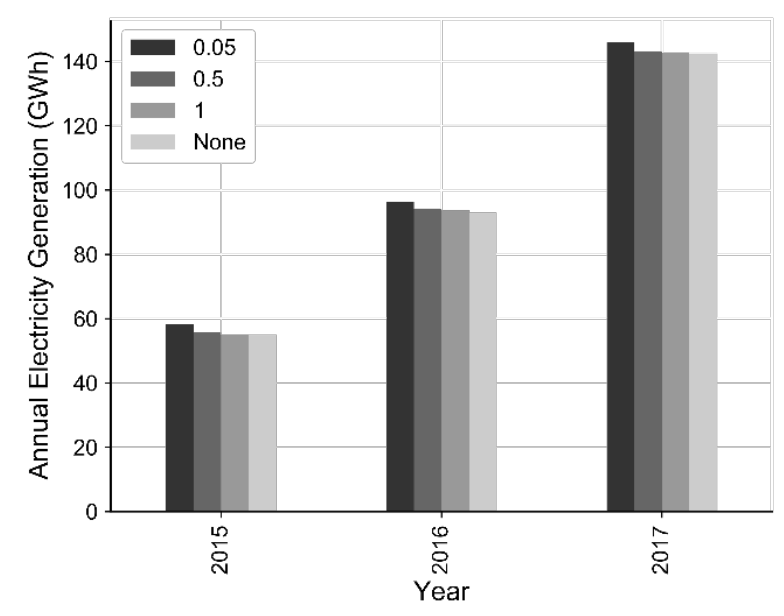

Figure 3. Annual generation as a function of flow constraint

We investigated a baseline run and three flow-constraint sensitivities, as follows:

- None: no downstream flow limitations (traditional load-following operation)

- 1: downstream flows were allowed to increase (decrease) by up to $100 \%$ of nominal

- 0.5 : downstream flows were allowed to increase (decrease) by up to $50 \%$ of nominal

- 0.05 : downstream flows were allowed to increase (decrease) by up to $5 \%$ of nominal.

We performed optimizations for all 3 years to help ensure robustness across dry (2105), nominal (2016), and wet (2017) years, and assessed the impacts on both generation and net revenues.

Figure 2 illustrates how the downstream flow constraints affect annual profits. As can be observed, it is difficult to visually distinguish any change in net revenues except in the case where the downstream flows are limited to $\pm 5 \%$ of the nominal flow. Even in the most restrictive case, the revenues are only reduced by $4 \%$, which is a number within the optimality gap of the models, and so we cannot say definitively that the revenues actually decrease, even under the most restrictive flow limitation.

Contrary to the impacts on net revenues, annual generation increases when flow constraints are imposed, increasing power generation by up to $6 \%$ across the three study years (see Figure 3 ). The reason for this is that the flow constraints shift some of the generation from peak to off-peak hours, flattening each generation facility's daily generation profiles (see Figure 4 for an example of how the peaks are shaved and the valleys filled as the downstream flow limits increase). The shift in generation from peak to nonpeak hours also reduces the use of storage reservoirs (the reservoirs are full more of the time, and, consequently, the generators operate at higher head, thereby producing more energy per volume of water). 


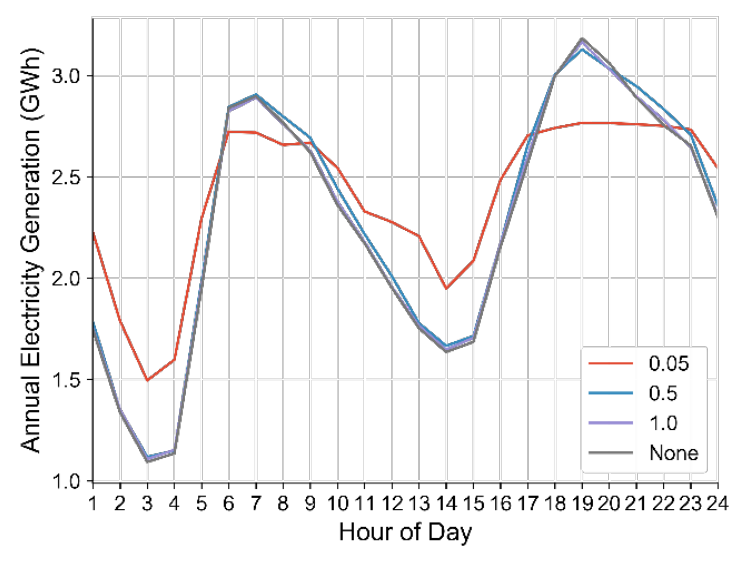

Figure 4. Changes in annual net revenues for a dry year (2015)

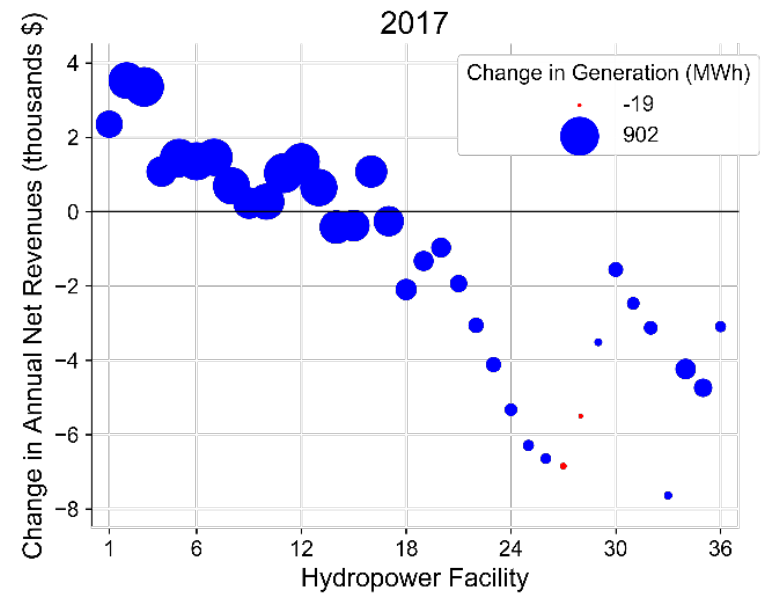

Figure 5. Changes in annual net revenues for a wet year (2017) when downstream flows are limited to $\pm 5 \%$ of nominal

Also of interest is how the generation patterns at the individual facilities shift with changes in the downstream flow constraints. Although the combined net revenue for the 36 facilities decreased slightly, the revenues of the individual facilities change markedly, with upstream facilities generating more at the expense of the downstream facilities. The combined changes largely cancel, with only a $4 \%$ change in net revenues even under the most extreme constraint (the $\pm 5 \%$ flow limit). An example of how the output of individual generators is impacted is shown in Figure 5, wherein the generation at the upstream units increases significantly (facility 1 is the unit that is the farthest upstream). The pattern of generation changes across dry (2015), typical (2016), and wet (2017) years is similar, with the largest increase in generation occurring at facility 2 and the largest decrease at facility 27 . The relative impacts to the generation at these two facilities is shown in Table 4. 
Table 4. Change in Annual Generation when Downstream Flows are Limited to $\pm 5 \%$ of Natural Flows

\begin{tabular}{cccc} 
Generation change (MWh) & $\begin{array}{c}\text { Dry Year } \\
(\mathbf{2 0 1 5 )}\end{array}$ & $\begin{array}{c}\text { Typical Year } \\
\mathbf{( 2 0 1 6 )}\end{array}$ & $\begin{array}{c}\text { Wet Year } \\
\mathbf{( 2 0 1 7 )}\end{array}$ \\
\hline Largest increase (station 2) & 856 & 956 & 902 \\
Largest decrease (station 27) & -103 & -10 & -19
\end{tabular}

As to why the impact of the flow constraints differs from earlier findings (i.e., the flow constraints had minimal impact on net revenues), we believe that this is a result of our model's ability to optimize all of the degrees of freedom provided by having a large number of small, flexible facilities in close proximity; however, additional research is needed to confirm this hypothesis.

\section{Reservoir Size}

To help ensure that the study results are not an artifact of the small reservoir sizes, we examined how reservoir size would affect revenues (see Figure 6). For a typical year with no downstream flow constraints, doubling the reservoir size at each facility increased net revenues by $7 \%$; whereas, quartering the reservoir size reduced the system's net revenues by $16 \%$. We observed that, although the individual reservoirs are small (each contains between 2 to 45 minutes of storage capacity), they add to the system's net revenue potential.

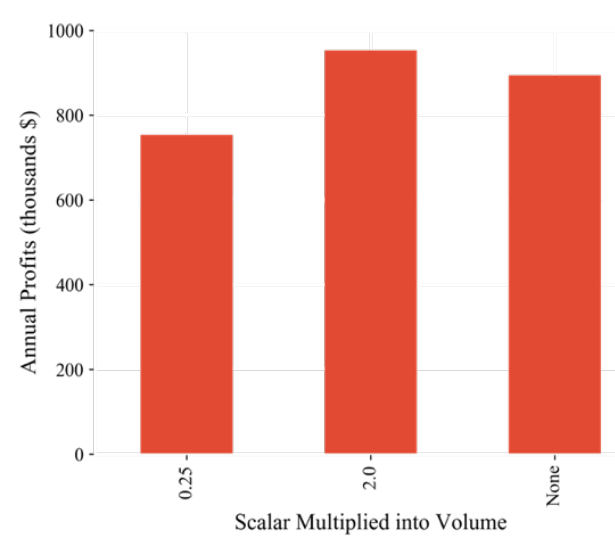

Figure 6. Annual net revenues as a function of reservoir size (typical weather year, 2016)

\section{Conclusion}

In this study, we analyzed how constraining the downstream flows of a hypothetical array of 36 cascading, small-scale hydropower facilities would affect net revenues. We built a model for the hypothetical system and examined its operations under typical, dry, and wet conditions.

We discovered that limiting the downstream flows to $\pm 50 \%$ of the river's natural flows had a negligible impact on net revenues ( $<1 \%$ reduction in net revenues), irrespective of hydrologic conditions, and even when downstream flows were limited to $\pm 5 \%$ of the river's natural flows, net revenues were only impacted by $4 \%$. These outcomes are significant in that they demonstrate 
how an array of small-scale hydropower facilities can be operated so that the facilities have minimal impact on natural stream flows. This work opens several new potential research areas including exploring how using small-scale hydropower can be used for stream restoration and investigating how multifacility optimization can be used to mitigate environmental impacts.

\section{Acknowledgements}

This work was authored [in part] by the National Renewable Energy Laboratory, operated by Alliance for Sustainable Energy, LLC, for the U.S. Department of Energy (DOE) under Contract No. DE-AC36-08GO28308. Funding provided by the U.S. Department of Energy Office of Energy Efficiency and Renewable Energy Water Power Technologies Office. The views expressed in the article do not necessarily represent the views of the DOE or the U.S. Government. The U.S. Government retains and the publisher, by accepting the article for publication, acknowledges that the U.S. Government retains a nonexclusive, paid-up, irrevocable, worldwide license to publish or reproduce the published form of this work, or allow others to do so, for U.S. Government purposes.

\section{References}

California Independent System Operator (CAISO), 2016. Fifth replacement electronic tariff (see https://www.caiso.com/Documents/Section4_RolesAndResponsibilities_asof_Oct1_2016.pdf).

CAISO, 2017. Locational Marginal Prices (LMP), node TH_NP15_GEN-APND OASIS Online: http://oasis.caiso.com/mrioasis/logon.do?reason=application.baseAction.noSession.

Craig M, Zhao J, Schneider G, Schneider A, Watson S, and Stark G, 2019. Net Revenue and Downstream Flow Impact Trade-Offs for a Network of Small-Scale Hydropower Facilities in California, Environmental Research Communications. 1011001.

Jager H I and Bevelhimer M S, 2007. How Run-of-River Operation Affects Hydropower Generation and Value, Environ. Manage. 40 1004-15.

Kern J D, Characklis G W, Doyle M W, Blumsack S, and Whisnant R B, 2012. Influence of Deregulated Electricity Markets on Hydropower Generation and Downstream Flow Regime, $J$. Water Resour. Plan. Manag. 138 342-55.

Natel Energy, 2018. (see https://www.natelenergy.com/ and https://www.natelenergy.com/turbines/for information about the company and its products).

U.S. Geological Survey, 2018. USGS 11413000 N Yuba R Bl Goodyears Bar, CA usgs.gov. 